Method To introduce 'The Macmillan Wellbeing Programme' funded by Macmillan Cancer Support, to develop, coordinate and deliver, over two years, a range of wellbeing and psychosocial programmes, giving great peer support, empowering better management of health and facilitating earlier access to hospice services. Impact is measured through an increase in the number of outpatients, referrals from non-Trinity professionals and outpatient volunteers.

Results Number of patients seen: 2013/2014: 286 2015/2016: 319 Target increase: 3\% Actual increase: 12\%

Referrals from non-Trinity professionals: 2013/2014: 108 2015/2016: 263 Target increase: 20\% Actual increase: 144\%

Number of outpatient volunteers: 2013/2014: 28 2015/2016: 39 Target increase: 20\% Actual increase: 39\%

Conclusion Launched in September 2015, the Wellbeing Programme has exponentially grown over the past year significantly exceeding the targets given. The introduction of the programme has results in establishing a community within Royal Trinity Hospice for patients, carers and families to become part of and feel supported through their individual journeys.

\section{P-51 THE LIVING WELL GROUP: ENCOURAGING WELLBEING THROUGH SELF-MANAGEMENT AND SOCIALISATION}

Chenise Moyston, Barbara Littlechild. Royal Trinity Hospice, London, UK

\subsection{6/bmjspcare-2016-001245.75}

Background Within the development of out-patient services in collaboration with the Macmillan Wellbeing programme at the hospice, the occupational therapy department established and assisted in the development of a Living Well Group.

Self-management of symptoms can allow patients and carers effected by life-limiting illness autonomy and improved quality of life and group sessions can facilitate socialisation and peer support. Aims

- Provide a multidisciplinary programme teaching selfmanagement techniques for a wide range of symptoms

- Provide a space for socialisation and peer support

- Identify potential need for referral to specialist services

- Include outpatients, carers and inpatients

- Improve general wellbeing.

Method A seven-week rolling programme was designed, each week covers a different topic and is led by a different professional, and a volunteer is also present for additional support.

\begin{tabular}{ll}
\hline Subject of Session & Facilitated by \\
\hline Fatigue and sleep & Occupational therapy \\
Anxiety and stress & Patient and Family Support Team \\
Breathlessness & Physiotherapy \\
Open nurse session & Outpatient nurse \\
Complementary therapy & Complementary therapy \\
Spiritual care & Spiritual Care Lead \\
Open session and benefits advice & Occupational Therapy and Welfare Advisor \\
\hline
\end{tabular}

Each session lasts 1.5 hours including; one hour focusing on teaching and advice for self-management related to the subject, encouraging active participation, discussion and peer support. 30 minutes break when socialisation between participants is encour- aged, cake and refreshments funded by Macmillan further encourage a relaxed environment.

Results Three cycles of the group are complete with a total of 25 attendees; 19 outpatients, three carers and three inpatients. Using an informal referral process has made it easy for external services to refer into the group thus broadening outreach and supporting partnerships with our communities.

A patient satisfaction survey was completed at the end of each session which provided the following feedback:

\begin{tabular}{ll}
\hline User comments & Potential wider context \\
\hline "I find it difficult to trust...But I have & Improved quality of life and wellbeing, \\
formed valuable friendships due to this & peer support and socialisation \\
group" & Better self-management of symptoms, \\
"I always take one thing away with & interactive learning, improved quality of \\
me" & life and wellbeing \\
"I wish the group was longer" & Enjoyment and improved quality of life, \\
"I enjoy listening to others" & further involvement with outpatient \\
& services. \\
& Peer support, shared learning, \\
& socialisation \\
\hline
\end{tabular}

Following on from the group four were then referred to other services where they could access more detailed and specialist support.

Conclusion The next cycle will commence July 2016, with the addition of dietary advice session. With ongoing advertising and partnerships with our local communities there is potential for the group to grow and remain a feature of the hospice outpatient service, it is clear that self-management techniques, socialisation and peer support are valued by participants.

With ongoing evidence supporting self-management of symptoms in palliative care and socialisation for improved wellbeing, groups such as the 'Living Well Group' are significantly relevant and could further support hospice care.

\section{P-52 OUR LIVING WALL - ART, FUN, STORIES AND FEELING CONNECTED}

Sabine Schwaebisch. Helen and Douglas House, Oxford, UK

\subsection{6/bmjspcare-2016-001245.76}

Our Living Wall (OLW) is a communal art wall at the heart of a children's hospice. We wanted to see whether a wall like this could impact on the happiness of children who visit.

We created a huge wall made of large removable jigsaw pieces. Children and their families, with staff help, take a piece and make it their own, through paint, stickers, images, etc., before putting it back on the wall. All pieces are photographed; next to the wall and online is a rolling exhibition of past pieces. When the wall is full, the child/family can take their piece home or it can be recycled.

We are acutely aware of the challenges faced by these children (limited chances to play, lack of control, low self-esteem, limited social connexion) and wanted to respond to these in a fun and creative way. The intention is for OLW to be as inclusive as possible, accessible to all children (0-18) with life-limiting conditions, regardless of age, ability, illness or background.

Our Living Wall has been up and running since April 2015, with over 100 pieces created so far. 